\title{
Educar en la sociedad actual ${ }^{*}$ Educating at today's society
}

\author{
Dr. Guillermo Jaim Etcheverry ${ }^{a}$ \\ http:/ /dx.doi.org/10.5546/aap.2012.35
}

La educación es una actividad estrechamente relacionada con la labor del pediatra ya que sus protagonistas son, precisamente, quienes están a su cuidado.

Toda vez que se hace referencia al futuro, se menciona la importancia de la educación para el desarrollo de las personas y de la sociedad. Sin embargo, la educación sólo logra atraer fugazmente la atención del público cuando se produce algún hecho anómalo. No creo necesario extenderme sobre los signos evidentes de que la Argentina ha ingresado al nuevo milenio con serios problemas en la cantidad de personas educadas con las que cuenta así como en la calidad de la educación que esas personas reciben.

Tan grave deterioro así como las intolerables desigualdades sociales que se observan en materia de educación, deberían estimularnos a volver a reflexionar sobre las cuestiones esenciales. Evitar que la crisis actual termine configurando una verdadera tragedia, supone que, una vez más, nos propongamos analizar el sentido último de la educación, las expectativas sociales que la determinan $y$, sobre todo, los modos mediante los que encaramos la incorporación de las nuevas generaciones a la cultura.

¿Para qué educamos? Responde Hannah Arendt en su ensayo "La crisis en la educación": "Educamos para enfrentar la renovación constante que experimenta la sociedad debido a la llegada de nuevos seres". Señala que niños y jóvenes se presentan ante padres y maestros bajo la doble condición de seres biológicos en veloz proceso de maduración y, por otro lado, de "recién llegados" a un mundo cultural que los antecede y que les resulta extraño. Además de asumir la responsabilidad por el desarrollo de sus vidas, debemos, pues, introducir a nuestros hijos en un universo de significados. Para hacerlo, recurrimos a la ayuda de una instancia prepública, la escuela, que no es en un todo idéntica al mundo. En ella, los educadores, aunque no hayan construido ese mundo o lo prefieran distinto, asumen la responsabilidad de representarlo ante las nuevas generaciones. Su competencia consiste en conocerlo y en ser capaces de introducir en él a los demás. Pero su autoridad se funda en el hecho de asumir esa responsabilidad testimonial con respecto a la cultura. Como afirma Charles Péguy, el docente "no es un enviado del Estado ni de la sociedad, sino el representante de la humanidad y de sus obras, es el delegado de los poetas, de los científicos, de los artistas". Los docentes cumplen su tarea en nombre de una colectividad que hoy se resiste a respetar el papel que desempeñan.

Al negarles ese reconocimiento y así asumir la responsabilidad de esa representación, nuestra generación expresa su desencanto ante la realidad, su desagrado frente a las cosas tales como son. No advierte que, precisamente, la esperanza de cambiarlas reside en lo nuevo que aporta cada generación. Hannah Arendt sostiene que por el bien de lo que hay de nuevo y revolucionario en cada niño, la educación debe ser capaz de preservar e
* Conferencia de Clausura, Congreso del Centenario de la Sociedad Argentina de Pediatría, Buenos Aires, 16 de septiembre de 2011. 
introducir ese elemento novedoso en un mundo viejo. Para eso, resulta imprescindible hacer consciente al "recién llegado" de las características de la realidad a la que se incorpora, proporcionándole los instrumentos de la cultura que le permitirán intentar cambiarla. El verdadero objetivo de la educación no es divertir al niño, sino rescatarlo de la agitación de la sociedad, asegurando las condiciones para que pueda entrar en posesión de su herencia.

Pero hoy no se intenta ya conformar a los seres humanos como sujetos autónomos, sino que se trata de satisfacer sus impulsos inmediatos, entreteniéndolos al menor costo posible. El principio del placer rige nuestras vidas. Avanza una sociedad que lo devora todo: bienes, ideas, celebridades. Reina la imagen, consagrando al videoniño y al cibernauta. Todo lo que antes era vivido directamente debe acceder a la representación. La permanencia del mundo, el sentimiento de lo real, se disuelven en las imágenes fugaces generadas por las nuevas tecnologías. Prisionero de un presente absoluto y global, desvinculado del pasado, el sujeto moderno es un "ser sin ombligo." Es preciso aceptar y comprender esos cambios profundos, que suponen una verdadera mutación de lo humano de la que somos a la vez protagonistas y testigos, pero eso no implica alentar la desvinculación de los recién llegados con una cultura que ha sido laboriosamente construida.

"¡Profesores, no nos hagan envejecer!", decían los muros del París del 68, convirtiendo el arte de heredar en un crimen contra la vida y la idea de transmisión en una enfermedad que nadie quiere padecer. Dijo Albert Camus al aceptar el Premio Nobel de Literatura en 1957: "Cada generación se siente llamada a reformar el mundo. La mía sabe que no lo hará, aunque su tarea es tal vez más ambiciosa. Consiste en evitar que el mundo se destruya a sí mismo."

¿Cómo advertir hoy que disponemos de un patrimonio digno de ser preservado, cuando la idea misma de herencia nos resulta ridícula a los gozadores que corremos detrás de la felicidad en lo nuevo, en el flujo incesante de imágenes y de placeres instantáneos? Posiblemente, el siglo XX marque el momento en que el ser humano deja de pensarse a sí mismo como heredero. Alain Finkielkraut en "L'ingratitude. Conversation sur notre temps" observa que "vivimos en la ilusión de creer que las personas logran la libertad renegando de toda herencia, de su pasado, de las obras maestras de la cultura".

La educación estaba sustentada en la idea directriz de la transmisión. Esta idea se ha ido dilu- yendo en las reformas propuestas para superar la realidad que conocimos, soluciones que, muchas veces, han agravado los problemas de la escuela.

Hannah Arendt identificó, ya a mediados de la década de 1950, ciertos rasgos esenciales en la crisis de la educación moderna que no han hecho sino agudizarse. Los niños forman un mundo aparte, en el que los adultos deciden inmiscuirse lo menos posible. La educación ya no corresponde a los maestros que conocen a fondo una disciplina, sino a los pedagogos, generalistas de la ciencia de la enseñanza. El propósito explícito de la educación no es más el de transmitir conocimientos sino el de sustituir el aprender por el hacer, el trabajo esforzado por el juego entretenido, los saberes concretos por la libre expresión de uno mismo.

Alain Touraine señala que, en la escuela actual, el paradigma de la comunicación ha herido de muerte el propósito de transmitir. La idea y hasta el vocablo mismo han desaparecido del discurso de los reformadores de la educación porque, en una sociedad que se pretende democrática, resulta cada vez más difícil admitir las jerarquías y pensar en la trascendencia. En una sociedad signada por el relativismo cultural y moral, discriminación y jerarquía son conceptos prohibidos pero ellos siguen siendo esenciales para desarrollar en los alumnos el espíritu crítico. Por eso, la escuela es cada vez más extraña al mundo actual ya que se trata de una institución asimétrica en el que los roles de los actores no son intercambiables. De serlo, la escuela perdería todo sentido.

Privilegiamos la espontaneidad, el intercambio, la comunicación, el debate. En lugar de preservar sus valores -el respeto al conocimiento, la reflexión, el análisis, el esfuerzo, la crítica- la escuela tiende a adaptarse tanto a la sociedad que termina siendo deglutida por ella. Obsesionados por comunicarnos, ya no nos proponemos transmitir. Transmitir requiere una ruptura profunda con el simple deseo de comunicar. Enseñar es más que informar, estudiar es más que informarse, aprender es más que expresarse. Debemos preguntarnos: ¿los estudios se degradan porque los alumnos son lo que son o los alumnos son lo que son simplemente porque hemos renunciado a enseñarles algo? ¿Las familias siguen enviando a las escuelas alumnos motivados por el deseo de aprender? ¿Seguimos considerando, como en el pasado, que la ignorancia es un mal?

Muchas corrientes pedagógicas sostienen que la enseñanza estructurada destruye la creatividad innata de los niños. Por eso, los maestros, hoy convertidos en "facilitadores", esperan que 
sus alumnos descubran el saber por sí mismos. La creatividad, definida como identificación y solución de problemas, es liberada del control del conocimiento, atribuido a los docentes que aún tienen la osadía de enseñar. Ese culto de la creatividad produce una nueva ortodoxia del aula, que reemplaza los desafíos intelectuales por los sentimientos, el pensamiento independiente por el conocimiento ya procesado. Como señala Paul Ricoeur, "la toma de distancia, la libertad con respecto a los contenidos transmitidos no pueden constituir la actitud inicial. Por la tradición nosotros nos encontramos ya situados en el orden del sentido y, por eso, también de la verdad posible".

Se impone una grotesca psicologización de la escuela que la ahoga en el afecto, en el culto de la autoestima. Se pide a los profesores que amen a los niños y no tanto a su saber. Esta desnaturalización de la relación docente-alumno es sintomática de la crisis institucional de la escuela y de su autoridad. Cuando los grandes profesores están habitados por el amor al saber y transmiten ese entusiasmo por el conocimiento que poseen, poco preocupa al alumno comprobar si lo quieren.

Muchos estudios sobre la escuela terminan por desterrar el estudio de la escuela. Indiferente y hasta hostil ante los contenidos del saber y la cultura que escapan a la observación, la enseñanza se va reduciendo a un conjunto de comportamientos y de actitudes, en general, desvinculados de las exigencias de inteligibilidad y de verdad. Esta clara tendencia a desintelectualizar la escuela se funda en consideraciones acerca de la realidad social que transforman un oficio humanista, el del maestro, en uno humanitario. Es que, como afirma Marcel Gauchet, "la idea de humanidad se ha disociado de la idea de cultura. No la necesitamos para existir. Estamos expuestos a una ola de privatización que nos estimula a vivir por y para nosotros mismos $y$, sobre todo, de no perder nuestro tiempo en tratar de comprender lo que nos rodea."

Pero, paradójicamente, cuanto más se invoca al igualitarismo, más se consolida un sistema desigual. ¿Cómo se puede afirmar que en la escuela son secundarias la instrucción y la transmisión de la cultura sin comprender que esta deserción supone el retorno inevitable de los privilegios? Corremos el riesgo de que la escuela moderna deje que la sociedad exterior sancione despiadadamente las desigualdades, como lo advirtieron claramente muchos teóricos marxistas, entre ellos Antonio Gramsci, quien afirmó que el progresismo político requiere una actitud conservadora en la educación.
La concepción que sostiene que el interés del alumno es el principal conductor de la enseñanza nos lleva a complacer su deseo de reconocerse en la escuela, de enfrentar en ella solo el paisaje que ya le es familiar porque es el que habita gracias a los medios de comunicación. Buscamos interesar a los alumnos en lo que ya les interesa. Dejamos de creer en la posibilidad de encontrar una motivación genuina en la fuerza del conocimiento y en el poder de crítica que abre la cultura. Si el criterio de evitar el aburrimiento es el que guía la enseñanza, abandonaremos el pasado en aras de lo que es actual, reduciendo la escuela a un lugar de consumo del presente, que aliente la pura expansión de lo que ya se es o, más bien, de lo que se cree ser. Porque la confusa subjetividad juvenil, hoy modelada sobre la base de la voraz apelación consumista y publicitaria, termina por afirmar la propia voluntad de ser así como se es, rechazando todo intento de dejarse modificar por otros saberes, de confrontar con la alternativa que ellos pueden representar.

Como la idolatría del progreso técnico nos convence de que el conocimiento está al alcance instantáneo de todos y de que se hace rápidamente obsoleto, pretendemos enseñar "habilidades" en un vacío casi total de saber. Es obvio que el mundo cambia rápidamente pero, sin contar con conocimientos básicos, no podremos construir sobre ellos ni enfrentar nuevos desafíos. Resulta preciso adaptarse a los cambios, pero abandonados al entusiasmo modernizador, corremos el riesgo de intentar transmitir un futuro vago. Por eso, es preciso vincular esa exigencia de transmisión al estímulo de un valor esencial: la pasión por comprender.

Posiblemente debamos volver a pensar que corresponde a la escuela enseñar a los niños cómo es el mundo en lugar de instruirlos exclusivamente en el arte de vivir. Esta apelación a su misión fundamental parece extemporánea porque hemos hecho de la escuela un espejo de la sociedad o, más bien, del mercado. En un artículo publicado en Le Monde, "A l'adresse de Claude Allegre", Regis Debray, famoso revolucionario de los años 60, sostuvo: "No es seguro que signifique progresar convertir la escuela en un club socio-educativo, transformar al alumno en cliente, la actividad docente en mero ejercicio de relaciones humanas, al profesor en proveedor de amenidades y a la transmisión de conocimientos en una oferta por modificar de acuerdo con la demanda."

Si advertimos que toda sociedad depende de la transmisión cultural para progresar y para 
transformarse, la escuela debe persistir en su intento de proporcionar a las personas las imprescindibles brújulas intelectuales que les permitan orientarse en el mundo, rehusando dar por conocido lo que ella debe dar a conocer. Para que los jóvenes se puedan convertir en adultos, adquirir autonomía de juicio y devenir ciudadanos, es necesario que sean puestos en posesión de una herencia en la que insertarse. El alumno atento y estudioso no debe ser reemplazado por el niño pedagogo, sociólogo y psicólogo. Deberíamos regresar a la concepción de la educación que expresó hace 2800 años Hesíodo, poeta griego contemporáneo de Homero: "Educar es ayudar a una persona a ser lo que es capaz de ser."

En la conciencia social se desdibuja cada vez más la concepción de que a la escuela se asiste, antes que nada, a aprender asuntos definidos que no coinciden con todas las funciones, ocasiones y apetencias de la existencia cotidiana. Por eso se olvida que, para establecer distinciones y diferencias, para escapar a una ciega identificación con la inmediatez, es esencial mantener en ella ciertos límites y excluir ciertas conductas. Hoy la escuela es estimulada a tomar como propios todos los modelos de comportamiento corriente, a hacerse cargo de las costumbres de la vida diaria, a sustituir a las familias, a confundirse con la experiencia cotidiana. En cambio, para lograr su propósito, la educación debería tomar en cuenta la separación que existe entre escuela y vida cotidiana, distinguiendo claramente su lógica de la que impera en el ámbito político de la vida pública. Sólo así podremos aplicar a la educación el concepto de autoridad, sustentado, como se ha dicho, en el compromiso de dar testimonio de una cultura cuya representación asumimos ante los recién llegados.

Cuando la pedagogía niega tanto esta distinción entre escuela y vida cotidiana como el esfuerzo que implica mantenerla, se convierte en demagogia. A las tendencias predominantes, se debería responder firmemente: la escuela debe seguir siendo un sitio de extrañamiento. Un espacio de desaceleración.
Conviene recordar las palabras de Jacques $\mathrm{Mu}-$ glioni en "L'école ou le loisir de penser": "La escuela no es la apertura, como está de moda afirmar. Es la separación. Preservar la independencia de la escuela con respecto a la sociedad exterior es preservar el futuro e inclusive, prepararlo." Esta idea debe sostenerse aún más firmemente en momentos en que lo contemporáneo ejerce sobre los niños tan fuerte presión. La escuela debe resistir a los prejuicios, a las certidumbres, a la vulgaridad del presente.

De otro modo, arrastrados por esta ola de velocidad creciente, los jóvenes pueden llegar a creer que el conocimiento e incluso el mundo físico y social son sencillos y fácilmente accesibles. Quedarán indefensos, a merced de la codiciosa industria cultural que hoy los manipula a su voluntad.

Aunque el contraste resulte traumático, la escuela debe ser concebida como ese ámbito de resistencia, de tozuda afirmación de las cualidades humanas ante la amenaza de su desaparición en el mundo actual. La escuela debe encabezar la cruzada de oposición al conservadorismo despiadado, que hoy nos tiraniza bajo la máscara del imperativo del movimiento y el cambio.

En una época acelerada en que el "academicismo de la ruptura" está de moda, los verdaderos revolucionarios posiblemente sean quienes retoman el ritmo lento que les permite escuchar mejor la voz de las herencias. Enseñar consiste en tejer esos lazos entre los antiguos y los nuevos. Sobre todo, en transmitir esa herencia cultural que confiere al hombre la capacidad de comprender una realidad compleja así como de renovar un mundo tan injusto sobre cuyo incierto destino tenemos una grave responsabilidad común.

Estas ideas no son sino la reiteración de las que ya he expresado en muchas ocasiones y recurriendo a los más diversos medios. He querido volver sobre ellas cuando esta Sociedad de Pediatría, al celebrar su primer centenario, se ocupa del futuro pero lo hace sin olvidar que quienes la integran tienen genuino derecho a reclamar la rica herencia que les pertenece. Creo interpretar que ese ha sido el sentido profundo de esta gozosa celebración. 